\title{
O discurso pedagógico na ditadura militar: Educação Moral e Cívica \& currículo escolar
}

\author{
The pedagogical discourse in military dictatorship: Moral and Civic \\ Education \& school curriculum
}

\author{
Márcia Helena Sauaia Guimarães Rostas* \\ Instituto Federal de Educação, Ciência e Tecnologia Sul-Rio-Grandense
}

Alexandre Kerson de Abreu** Instituto Federal de Educação, Ciência e Tecnologia Sul-Rio-Grandense

Resumo Este artigo tem como objetivo analisar, a partir de uma abordagem qualitativa, o funcionamento do discurso pedagógico utilizado na disciplina de Educação Moral e Cívica, implantada nas escolas brasileiras durante o regime militar. Para isso, será realizado um estudo de caso sobre um dos livros didáticos utilizados na época: "Educação Moral e Cívica", dos autores Otto Costa, Felipe N. Moschini e José C. Paixão. Por meio da Análise de Discurso (AD) de linha francesa, procuraremos mostrar os efeitos de sentido produzidos pelo sujeito discursivo e seu interlocutor, observando as diferentes formações discursivas presentes, o processo de interpelação do sujeito pela ideologia e o conceito de interdiscurso/memória discursiva.

PALAVRAS-ChAVE: Discurso pedagógico; Análise de discurso; Currículo; Educação Moral e Cívica.

\footnotetext{
Abstract This article aims to analyze, from a qualitative approach, the operation of the pedagogical discourse used in the discipline of Moral and Civic Education, implanted in Brazilian schools during the military regime. Will be held a case study on one of the didatic textbooks used that time "Moral and Civic Education," of the authors Otto Costa, Felipe N. Moschini and Joseph C. Passion. Through Discourse Analysis (DA) of the French line, try to show the effects of meaning produced by discursive subject and his interlocutor, watching the different discursive formations present, the process of interpellation of the subject by ideology and the concept of interdiscourse/discursive memory.

KEYWORDS: Pedagogical discourse; Discourse analysis; Curriculum; Moral and Civic Education.
} 


\section{Introdução}

O período ditatorial que vigorou no Brasil entre 1964 e 1985 deixou marcas profundas na história do país. O regime militar autoritário instaurou uma era de violência, censura, supressão de direitos constitucionais, perseguição política e repressão. Sob a bandeira de uma nação livre e democrática, as forças armadas assumiram o comando apoiadas por setores conservadores da sociedade, entre eles, empresários, banqueiros e Igreja Católica. O foco era combater o socialismo e evitar um possível golpe comunista num período conhecido por Guerra Fria, no qual capitalismo e socialismo disputavam a hegemonia mundial.

Apoiados pelos Estados Unidos e seus aliados, os militares implementaram no Brasil uma política de caráter desenvolvimentista e a Doutrina de Segurança Nacional, que dava o respaldo necessário para o uso da força e de outras arbitrariedades em nome da defesa da democracia e soberania nacional.

A ditadura provocou traumas. Na educação, considerada um setor estratégico para a manutenção do sistema político da época, a criação da disciplina Educação Moral e Cívica pode ser considerada um símbolo da prepotência e da falta de interesse das forças armadas em preparar uma geração capaz de pensar e refletir sobre os verdadeiros problemas do país.

O Decreto-Lei 869/69, que obrigava o ensino da disciplina nas escolas, foi apenas um dos inúmeros desmandos verificados neste capítulo da história brasileira, também conhecido como Anos de Chumbo. Neste artigo, vamos relacionar aspectos deste período do regime militar e sua influência na educação, por meio de características marcantes do discurso pedagógico utilizado nas instituições de ensino da época. Com o auxílio da Análise de Discurso (AD) de linha francesa, buscaremos ultrapassar o nível da superfície e penetrar nas amarras do discurso, buscando aquilo que está implícito e revelando o processo de produção de sentidos.

\section{Educação Moral e Cívica e currículo: preparando o terreno ideológico}

O cenário da década de 60 evidencia uma polarização entre dois países: Estados Unidos e a extinta União das Repúblicas Socialistas Soviética.

Com o apoio de organismos internacionais, a articulação norte-americana em torno de um ideal desenvolvimentista ganhou força. Pregavam uma campanha global contra o comunismo. Este foi o alicerce em que se ergueu o chamado Rearmamento Moral, difundido em vários cantos do mundo, sobretudo na América Latina. A imprensa teve um papel estratégico na divulgação do movimento. Importantes jornais do Brasil serviram como meio de veiculação de propaganda desses propósitos, como ilustra abaixo o enunciado de um material assinado pelo marechal Juarez Távora e encartado no periódico O Estado de S. Paulo, de 12 de agosto de 1962, comentado por Ferreira (2006, p. 132) em seu livro "João Goulart: entre a memória e a história”. 
A escolha hoje é entre a tirania brutal do comunismo, o suicídio coletivo por meio da guerra atômica, ou o renascimento global através do Rearmamento Moral. O comunismo jamais vencerá. Nosso destino é unir nossa atenção e dar ao mundo o Rearmamento Moral. Essa é a solução final.

No cenário da educação, uma das medidas do governo militar foi a criação, em 1969, do Decreto-Lei 869, que tornava a Educação Moral e Cívica disciplina obrigatória nas escolas brasileiras, em todos os graus, modalidades e sistemas de ensino O teor desta legislação era o reflexo do contexto político, econômico e social daquele período, tendo a disciplina de Educação Moral e Cívica à incumbência de transmitir à sociedade um conjunto de atitudes e comportamentos representativos de um ideal de "ordem" estabelecido pelo governo, além de servir como mecanismo de reprodução e legitimação do regime militar.

Rezende (2013) ratifica o importante papel da educação neste cenário. Segundo a autora, a pretensa integração e ordem nacional deveriam ter a escola como um de seus pilares, cujo objetivo era "legitimar o regime; o que significava adaptar e ajustar as gerações vindouras aos valores concebidos como essenciais pela nova ordem social que estaria sendo criada" (p. 46).

Recorrendo a Foucault, podemos inferir que a implantação da disciplina de Educação Moral e Cívica funcionou como um eficiente instrumento de poder. O poder está presente em todo o corpo social, "produz coisas, induz ao prazer, forma saber, produz discurso" $(2008$, p. 8).

Um dos livros adotados nesta época por dezenas de escolas brasileiras foi "Educação Moral e Cívica". Escolhida para ser o corpus deste artigo, a obra foi escrita por Otto Costa, Felipe Moschini e José Paixão e publicada em 1975. Logo de início, nas "Considerações oportunas", os autores fazem questão de ressaltar que a obra está rigorosamente de acordo com o programa oficial de Educação Moral e Cívica, elaborado pelo Conselho Federal de Educação em 1971.

O conteúdo programático traz temas e subtemas relacionados, de maneira geral, ao homem em seus diversos aspectos, a noção do valor moral e seus reflexos na vida individual, o caráter, a moral e a religião, como pontos fundamentais para a constituição da personalidade humana.

A utilização da Educação Moral e Cívica como instrumento de legitimação de poder e propagação dos ideais da ditadura militar encontra respaldo em Chervel, para quem a disciplina escolar “[...] comporta não somente as práticas docentes da aula, mas também as grandes finalidades que presidiram sua constituição e o fenômeno de aculturação de massa que ela determina [...]" (1990, p. 184).

Abordaremos a seguir algumas reflexões sobre o currículo como documento de identidade, a partir das teorias tradicionais do currículo, destacando também importantes características de funcionamento do discurso pedagógico sob a ótica da teoria de Basil Bernstein. 


\title{
Discurso pedagógico a serviço do poder
}

A ditadura militar, apoiada por setores conservadores da sociedade, defendia o cristianismo e combatia o comunismo e as atitudes consideradas subversivas ao sistema, em nome de uma suposta soberania nacional. Ganhavam cada vez mais espaço os impopulares Atos Institucionais como forma autocrática de manutenção do poder. As escolas, como aponta Althusser (1983), funcionam como aparelho ideológico do Estado e são um importante mecanismo de reprodução ideais capitalistas. Sobre o papel ideológico das instituições de ensino, Silva (2003, p. 31-32) diz que:

\begin{abstract}
A escola atua ideologicamente através de seu currículo, seja de uma forma mais direta, através de matérias mais suscetíveis ao transporte das crenças explícitas sobre a desejabilidade das estruturas sociais existentes, como Estudos Sociais, História e Geografia, por exemplo; seja de uma forma mais indireta, através de disciplinas mais "técnicas", como Ciências e Matemática.
\end{abstract}

De acordo com Silva (2003) a Educação Moral e Cívica encaixa-se perfeitamente dentro desta atuação ideológica da escola, como uma disciplina transmissora de crenças e valores, cuja proposta é de manutenção da estrutura social e econômica vigente. Essa análise marxista da educação, segundo Silva (2003), instaura uma forte relação entre escola e economia e entre educação e produção.

O conceito de correspondência de Bowles e Gintis (1981) avança as discussões sobre currículo e apontam uma estreita relação entre escola e produção. Em seus estudos, os teóricos defendem a ideia de que a instituição de ensino reproduz as relações capitalistas de trabalho e incutem essas atitudes na mente dos estudantes.

No esquema proposto, a escola trabalharia para a qualificação de um trabalhador subordinado e ajustado ao sistema capitalista, exigindo dos alunos obediência às ordens, assiduidade, pontualidade e confiabilidade. Da mesma forma, na outra ponta, o estudante pertencente à elite tem enfatizado em sua aprendizagem a capacidade de comandar, formular planos, ou seja, uma atuação de forma mais autônoma.

A visão dos autores reforçam as ideias de Bernstein (1996) sobre o papel da educação como instituição responsável pela produção e reprodução de injustiças sociais. Formulada por ele, a teoria do discurso pedagógico destaca um dispositivo que regula a comunicação pedagógica, suscetível a variação de contextos e ligado a ideologias. É esse dispositivo que estrutura o discurso pedagógico, a partir de regras distributivas, recontextualizadoras e de avaliação, como aponta Bernstein (1996).

$\mathrm{Na}$ constituição do discurso pedagógico aparecem ainda os discursos instrucional e regulativo. Bernstein explica que o discurso instrucional é aquele "que transmite as competências especializadas e sua mútua relação; chamaremos de discurso regulativo o que cria a ordem, a relação e a identidade especializadas" (1996, p. 258)

Desta forma, tendo como base as regras distributivas e recontextualizadoras e considerando a tensão e sucessivas repressões durante a ditadura militar, a escola, funcionando como aparelho ideológico de manutenção do poder, foi obrigada a adotar 
os livros didáticos chancelados pelo governo da época e se apropriar de discursos que pudessem cumprir os objetivos educacionais impostos. Lembrando que a escolha dos conteúdos programáticos dos livros didáticos, segundo Apple (1995), está atrelada às relações de dominação existentes. Sobre esse aspecto, Silva ressalta que:

Se a ideologia cedesse lugar ao verdadeiro conhecimento, o currículo e a sociedade seriam finalmente emancipados e libertados. Se pudéssemos nos livrar das relações de poder inerentes ao capitalismo, o conhecimento corporificado no currículo já não seria um conhecimento distorcido e espúrio. (SILVA, 2003, p. 149).

Forçados a assumirem o compromisso ideológico do regime militar, os professores que lecionavam a disciplina de Educação Moral e Cívica eram os responsáveis pela recontextualização dos discursos e ideais impostos à sociedade da época e por reproduzi-los aos alunos. Ao operacionalizar esses discursos nas esferas instrucional e regulativa, os docentes preparavam o terreno para um contexto de aprendizagem dos conteúdos estabelecidos pelo currículo da época, em consonância com os objetivos preconizados pelo Artigo no 2 do Decreto-Lei 869 de 1969.

\section{Análise de Discurso: a (s) outra (s) face (s) dos enunciados nos livros didáticos}

Ao falarmos de discurso pedagógico focamos a linguagem, seja ela verbal ou não verbal. Especificamente neste artigo, temos um conteúdo programático elaborado especificamente para a disciplina Educação Moral e Cívica, dentro de um contexto social e político de censura e repressão do regime militar. Como veremos a seguir, o discurso apresenta uma falsa transparência, já que a linguagem também não é transparente e está materializada na ideologia. Mergulhar nessa opacidade e desvelar as tramas presentes neste discurso é objetivo principal deste estudo, onde serão utilizados alguns dos principais conceitos da Análise de Discurso (AD) de orientação francesa.

Pêcheux (1997) concebe o discurso como um efeito de sentidos entre locutores e trata a linguagem como um sistema aberto onde se relacionam sujeitos e sentidos afetados pela língua e pela história. Dessa forma, na produção de sentidos em um discurso, deve-se levar em conta o sujeito e o contexto sócio-histórico e ideológico, ou seja, as condições de produção. Como o sujeito se constitui ideologicamente, não há como, na Análise de Discurso, determinar um sentido único, original, dado o caráter polissêmico da linguagem. "O sentido não existe em si mesmo [...], mas é determinado pelas posições ideológicas colocadas em jogo no processo sócio-histórico em que as palavras, expressões, proposições são produzidas [...]” (PECHÊUX, 1988, p. 144).

Em um discurso, essas posições ideológicas se comportam, em muitos momentos inclusive, como forças antagônicas, evidenciando a heterogeneidade do discurso. Aliás, a AD trata a linguagem como um lugar de conflito e opacidade, concebendo, assim, um sujeito descentrado, dividido, incompleto. E esse mesmo sujeito, na busca por sua completude e identidade, permite que se rompam os limites de sua formação discursiva. Pêcheux chama de formação discursiva 
[...] aquilo que, numa formação ideológica dada, isto é, a partir de uma posição dada numa conjuntura dada, determinada pelo estado da luta de classes, determina o que pode e deve ser dito (...) isso equivale a afirmar que as palavras, expressões, proposições, etc., recebem seu sentido da formação discursiva na qual são produzidas (...) os indivíduos são "interpelados" em sujeitos-falantes (em sujeitos de seu discurso) pelas formações discursivas que representam "na linguagem” as formações ideológicas que lhes são correspondentes. (PECHÊUX, 1988, p. 160-161).

O atravessamento de diferentes formações discursivas (FD) e a possível migração do sujeito de uma FD para outra mostram um sujeito heterogêneo e fazem com que as palavras mudem de sentido, sempre considerando as condições de produção do discurso e o momento sócio-histórico.

Diante dessa multiplicidade do sentido, a Análise de Discurso, aponta Orlandi (1999), procura compreender os processos de significação atuantes em um discurso, permitindo que outros sentidos sejam "escutados". A existência de diferentes sentidos está diretamente ligada ao momento sócio-histórico em que está posicionado o sujeito discursivo e a formação discursiva a que está filiado. Então, ratificando Pêcheux (1988), podemos afirmar que existe mudança de sentido quando os sujeitos estão inscritos em formações discursivas diferentes.

Nessa condição, ao dizer, ele dá indícios sobre a formação discursiva à qual está inserido - já que é interpelado pela ideologia - e pode assumir diferentes posições num discurso.

Sabendo que um discurso é atravessado por outros discursos (heterogeneidade discursiva) um sujeito, para se dotar de autonomia e ser a fonte do que diz, precisa assumir uma forma-sujeito, que de acordo com Pêcheux, trata-se de uma estrutura discursiva que dissimula o assujeitamento do sujeito.

[...] a tomada de posição não é, de modo algum, concebível como um "ato originário" do sujeito-falante: ela deve ser, ao contrário, ser compreendida como o efeito, na forma-sujeito, [...] da "exterioridade" do real ideológico-discursivo, na medida em que ela "se volta sobre si mesma" para se atravessar (1988, p. 171-172).

Essa posição assumida pelo sujeito, que afeta o sentido, refere-se às formações discursivas que, por sua vez, remetem a formações ideológicas, as quais compreendem o conjunto de representações e atitudes que dizem respeito às posições de classe em conflito umas com as outras (PÊCHEUX, 1997). A formação ideológica traz, então, consigo diferentes formações discursivas, que vão determinar o que pode e deve ser dito num determinado momento sócio-histórico, promovendo os possíveis e diferentes sentidos, como diz Pêcheux (1988).

A noção de formação discursiva ratifica a questão da interpelação do sujeito pela ideologia, um sujeito assujeitado, que tem a ilusão de que é a origem da produção do sentido, no entanto, "[...] se ele não se submeter à língua e à história ele não se constitui, ele não fala, não produz sentidos” (ORLANDI, 1999, p. 49). 
Ocorre aí um processo de apagamento, onde o que é dito é sustentado por formulações feitas anteriormente, mas esquecidas. Por isso é que o sujeito tem a ilusão de que é a origem daquilo que diz. Sujeito e sentido não são estáticos e estão sempre em movimento. Essa característica é possível porque o real da língua, como atesta Orlandi (1999), está sujeito a falhas e o real da história é passível de ruptura. "Daí dizermos que os sentidos e os sujeitos sempre podem ser outros [...]. Depende de como trabalham e são trabalhados pelo jogo entre paráfrase e polissemia" (ORLANDI, 1999, p. 37).

A afirmação de Orlandi traz à tona dois importantes conceitos, nos quais se dá o funcionamento da linguagem: paráfrase e polissemia. Segundo a autora, a paráfrase é a repetição e a reformulação de um enunciado com base em um mesmo dizer já sedimentado. Já a polissemia é o que ela chama de "o diferente", que promove o deslocamento e a ruptura dos processos de significação, jogando com o equívoco. É nessa tensão entre paráfrase e polissemia que sujeitos e sentidos se movimentam e passam a significar.

Junto com a formação discursiva vem também o conceito de interdiscurso ou memória discursiva, que são os diferentes saberes discursivos presentes e imbricados em uma formação discursiva. Esses discursos são oriundos de diferentes momentos históricos e lugares sociais e ideológicos.

Nas palavras de Orlandi, interdiscurso ou memória é

[...] aquilo que fala antes, em outro lugar, independentemente. Ou seja, é o que chamamos memória discursiva: o saber discursivo que torna possível todo o dizer e que retorna sob a forma do pré-construído, o já-dito que está na base do dizível, sustentando cada tomada de palavra. O interdiscurso disponibiliza dizeres que afetam o modo como o sujeito significa em uma situação discursiva dada (ORLANDI, 1999, p. 31).

Pêcheux (1988) trabalha o conceito de esquecimento associado à memória, para mostrar como é o funcionamento do discurso. A ideia é explicar que, no discurso, existe a retomada do já-dito pelo sujeito discursivo e que este, para se constituir ilusoriamente como sujeito consciente, que controla os sentidos do que diz, "esquece" (e precisa esquecer) que os sentidos já existem anteriormente e já estão historicamente constituídos. Fica claro aqui a interpelação do sujeito pela ideologia.

Sobre o esquecimento no discurso, Pêcheux (1988) diz que ele acontece de duas formas. O esquecimento número um, chamado de esquecimento ideológico, trata-se da forma como somos afetados pela ideologia, criando a ilusão de que somos a origem do que dizemos. De fato, como já foi colocado anteriormente, apenas retomamos sentidos preexistentes. Existe um apagamento de tudo o que faz referência ao exterior de nossa formação discursiva.

A outra forma, o esquecimento número dois, diz respeito à enunciação. $\mathrm{Ou}$ seja, está relacionado ao por que dizemos uma coisa e não outra. Através da chamada ilusão referencial, acreditamos que existe uma relação direta entre pensamento, lingua- 
gem, e o mundo. "[...] pensamos que o que dizemos só pode ser dito com aquelas palavras e não outras, que só pode ser assim” (ORLANDI, 1999, p. 35). O esquecimento enunciativo atesta que o modo de dizer não é indiferente aos sentidos.

\section{Metodologia e análise: mergulhando na teia do discurso}

Partindo da premissa de que a ideia não é procurar o "sentido verdadeiro, mas o real do sentido em sua materialidade linguística histórica" (ORLANDI, 1999, p. 59), utilizaremos, neste artigo, a Análise de Discurso (AD) de orientação francesa, para mostrar o deslizamento de sentidos e sua relação com as Formações Discursivas (FD). Além das FDs, mobilizaremos outros conceitos da $\mathrm{AD}$, como os esquecimentos $\mathrm{n}^{\circ} 1$ e $\mathrm{n}^{\circ} 2$ e o interdiscurso/memória discursiva.

O corpus é o livro "Educação Moral e Cívica", editado em 1975 e escrito por Otto Costa, Felipe N. Moschini e José C. Paixão. Como recorte, foi escolhido três enunciados da unidade V - "O Estado", que abordam, respectivamente, as temáticas Democracia, Comunismo e Cristianismo.

Dentro do dispositivo criado para análise, o objeto é atravessar o efeito de transparência da linguagem, mostrando o modo de funcionamento do discurso e a influência ideológica na produção de efeitos de sentido. Desta forma, serão destacadas palavras destes enunciados, como material simbólico de observação e análise.

\section{Enunciado 1}

"Se praticarem atos bons, receberão recompensa; se praticarem atos maus, receberão castigo. Daí, porque se diz que a liberdade, na Democracia, deve ser responsável, consciente, e não ilimitada e desenfreada, pois disso resultariam a desordem e a subversão" (p. 203).

No enunciado 1, identificamos a presença de uma FD Militar. Como característica, essa FD traz consigo a ideologia militar e coloca em oposição as expressões representativas de ação/atitude do cidadão, atos bons $x$ atos maus, e de consequência, recompensa $\times$ castigo.

Pela FD em questão, o sujeito discursivo coloca o cidadão brasileiro que vivia sob o regime militar na condição de um soldado, que deve estar ciente de sua contribuição para garantir a soberania nacional. Transgredir ordens e romper com os padrões disciplinares, em vez da recompensa, que seria a de uma nação próspera e democrática, receberia punições severas e "justificáveis" pela atitude desordeira e subversiva.

Levando-se em consideração as condições de produção do discurso, é possível inferir que a liberdade do cidadão da qual trata o enunciado não era total, estava condicionada àquilo que o regime militar pregava. Os Atos Institucionais (AIs) instituídos na época foram um mecanismo de poder criado pelo governo como forma de legitimar e legalizar as ações políticas e militares arbitrárias da ditadura. Ou seja, toda censura e repressão era justificada e tinha como bandeira a manutenção da ordem e da democracia. 
Além da FD Militar citada acima, pode-se identificar ainda uma FD Religiosa, visto que o sujeito discursivo utiliza as oposições atos bons $x$ atos maus e recompensa $x$ castigo como ações e consequências que podem também ser julgadas pela vontade de Deus. Aqui, essas palavras opostas são capturadas no interdiscurso, onde circulam discursos outros, no caso o religioso, e ganham uma nova construção de sentido sobre os sentidos anteriores, a partir das condições de produção atuais. Através dos esquecimentos $\mathrm{n}^{\circ} 1$ e $\mathrm{n}^{\circ} 2$, o sujeito discursivo acredita que é a origem do que diz e que somente essas palavras (e não outras) poderiam ser utilizadas para atingir seu interlocutor. Assim, o efeito de sentido neste enunciado remete à ideia de que o poder do regime militar, bem como as suas ações, então, passa a ser revestido também pela vontade de Deus. E agir contra ou a favor desta "vontade divina" pode trazer consequências ruins ou boas, respectivamente.

\section{Enunciado 2}

"É por isso que o Comunismo, bem como as demais teorias totalitárias devem ser combatidas com todas as forças, porque pregam a prevalência dos valores materiais sobre os imateriais" (p. 204).

Neste enunciado predomina uma FD Militar, onde as palavras combatidas e forças são recrutadas do discurso bélico pela memória discursiva e passam a ter um novo efeito de sentido, sugerindo que o cidadão brasileiro lute até o fim contra o inimigo, no caso o comunismo, que na época disputava o cenário político com o capitalismo, modelo econômico defendido pela ditadura militar sob a égide da democracia desenvolvimentista e do progresso.

O efeito de sentido extraído neste enunciado coloca o comunismo como uma ameaça à liberdade, à dignidade humana, à religião, ao espírito e a Deus, tidos no capitalismo como bens hierarquicamente superiores. Inverte a lógica do jogo e elege o comunismo como vilão, defensor da ideia de que os bens econômicos devem ser controlados pelo Estado, prevalecendo os valores materiais sobre os imateriais, em detrimento dos bens espirituais, morais e intelectuais.

O alinhamento político dos escritores (posição-sujeito) de "Educação Moral e Cívica" com o regime militar da época e sua respectiva ideologia deixa transparecer uma FD Militar, que traz consigo escolhas - não intencionais, já que o sujeito na $\mathrm{AD}$ é assujeitado - de determinadas palavras no lugar de outras, sempre levando em consideração as duas formas de esquecimento: o ideológico e o enunciativo.

\section{Enunciado 3}

Não se pode esquecer, por outro lado, que foi o Cristianismo, o maior movimento filosófico-religioso de todos os tempos, que nos legou os princípios sadios de amor a Deus e ao próximo, de solidariedade e de humanidade, que devem informar a verdadeira Democracia, voltada para o bem-estar e a felicidade de todos" (p. 206).

Nas pesquisas teóricas para determinação da FD deste enunciado, uma informação importante determinou a condução dos trabalhos: a ligação de um dos 
escritores do livro à área religiosa. Filgueiras (2006) destaca que a disciplina de Educação Moral e Cívica foi implantada sem estar alicerçada em uma ciência de referência, e os autores dos livros didáticos eram oriundos das mais diferentes áreas. Da lista faziam parte professores do magistério, de história, geografia e filosofia; professores universitários; diretores; orientadores educacionais; sociólogos; membros do Exército e até padres. No grupo dos religiosos estava Felipe N. Moschini, padre ligado à Federação do Comércio do Estado de São Paulo e conferencista de diversos ciclos de estudos sobre os problemas nacionais, organizados pela entidade supracitada.

Desta forma, Moschini, ao lado de Costa e Paixão, trabalhou na interpretação dos programas para a disciplina seguindo suas orientações ideológicas. Portanto, não causou surpresa o fato de a FD predominante neste enunciado ter sido a Religiosa. Partindo desta identificação, ao enfatizar o Cristianismo como maior movimento filosófico-religioso e omitir outras religiões, o sujeito discursivo produz um efeito de sentido que traz que somente o cidadão que segue os preceitos do Cristianismo é capaz de ter princípios considerados sadios, dentro de uma normalidade desejada. Já o cidadão que, por ventura, praticasse outra religião, estaria à margem da sociedade, cultivando princípios tidos como não saudáveis para o corpo e a alma e afastado de Deus.

Conforme Brandão (1997), a memória discursiva, tendo em vista uma determinada formação discursiva e os diferentes discursos imbricados nela, determina aquilo que deve emergir de um contexto histórico anterior e ser atualizado em um outro, deixando de lado o que não deve ser trazido à tona. A FD Religiosa, portanto, ao eleger a palavra Cristianismo, traz implícito um não-dito (mas presente), que complementa o que foi dito. Do mesmo modo, levando em conta os esquecimentos de ordem ideológica e enunciativa, opera na constituição de um efeito de sentido que liga as outras religiões a uma falsa Democracia, em oposição à verdadeira Democracia.

Assim, o Cristianismo funcionava como um aliado do regime militar na manutenção da ordem e da democracia e no combate ao comunismo, cujos defensores eram rotulados de violentos, desordeiros, marginais e "comedores de criancinhas", numa alusão à prática do canibalismo como um ato ofensivo a Deus e a valores como solidariedade e humanidade.

\section{Considerações finais}

Após a análise dos três enunciados selecionados da unidade V - "O Estado", foi possível observar externamente o fenômeno, de forma crítica, com o auxílio da Análise de Discurso (AD) de orientação francesa. Ao penetrar na opacidade do discurso pedagógico praticado na disciplina de Educação Moral e Cívica, verificamos em seu funcionamento uma forte impregnação ideológica militar e religiosa, que marcou o período ditatorial brasileiro. Mostramos que as palavras estão a serviço da ideologia e que o sujeito não é a origem do que produz. É assujeitado, heterogêneo e está a todo o momento interpelado pela ideologia e atrelado a formações discursivas.

Nesse processo, observou-se que as palavras grifadas para análise estão alicerçadas no interdiscurso e ligadas à formação ideológica. Ao optar por esta ou aquela 
palavra, tendo em vista o efeito que pretende sobre o seu interlocutor, o sujeito discursivo é afetado pelo esquecimento $n^{\circ} 1$, gerando a ilusão de que ele é a origem do que diz, e em seguida pelo esquecimento $n^{\circ} 2$, que o faz pensar que somente aquela escolha poderia surtir o efeito esperado. Existe um processo de apagamento de tudo o que já foi dito anteriormente e a memória discursiva age constituindo o sentido.

Portanto, pelo viés da $\mathrm{AD}$, ratificou-se que a disciplina de Educação Moral e Cívica foi implantada com a finalidade de transmitir à sociedade um conjunto de atitudes e comportamentos representativos de um ideal de "ordem" estabelecido pelo governo, além de servir como mecanismo de reprodução e legitimação do regime militar.

No entanto, o diferencial deste artigo foi trazer à tona os efeitos de sentido produzidos pelo sujeito-discursivo. Pelas formações discursivas identificadas, os enunciados que constituíam o discurso pedagógico daquele período colocavam os alunos em uma situação na qual o único caminho era seguir a doutrina do regime militar, sob pena de estarem pecando contra Deus e cometendo crimes contra a Pátria.

Instrumentalizar o jovem estudante para reflexões mais críticas sobre qual o caminho mais profícuo para o desenvolvimento e bem-estar de seu país não foi uma prática valorizada naquela época. $\mathrm{Na}$ educação, a imposição de uma disciplina descontextualizada e crivada de conceitos que pudessem levar a geração ora em formação a uma estado de conformidade foi algumas das facetas mais cruéis do regime militar, que azeitou a engrenagem do discurso pedagógico para justificar uma organização política perversa, autoritária e antidemocrática. $\mathrm{O}$ comando não estava nas mãos de Deus. Homens de farda escreviam a história de toda uma nação.

\section{Referências}

ALTHUSSER, L. Posições - 1. Rio de Janeiro: Graal, 1978.

. Aparelhos Ideológicos de Estado. Rio de Janeiro: Graal, 1983.

APPLE, M. Trabalho docente e textos: economia política das relações de classe e de gênero em educação. Tradução de Tomaz Tadeu da Silva, Tina Amado, Vera Maria Moreira. Porto Alegre: Artes Médicas, 1995.

BERNSTEIN, B. A estruturação do discurso pedagógico: classe, códigos e controle. Tradução de Tomaz Tadeu da Silva e Luis Fernando Gonçalves Pereira. Petrópolis: Vozes, 1996. v. IV.

BOWLES, S.; GINTIS, H. La instrucción escolar em la América capitalista. México: Siglo XXI, 1981.

BRANDÃO, H. H. N. Introdução à análise do discurso. Campinas: Editora da Unicamp, 1997.

CHERVEL, A. A história das disciplinas escolares: reflexões sobre um campo de pesquisa. Revista Teoria \& Educação. Porto Alegre, no 2, p. 177-229, 1990.

COSTA, O.; MOSCHINI, F. N.; PAIXÃO, J. C. Educação Moral e Cívica. São Paulo: Editora do Brasil, 1975.

FERREIRA, M. M. João Goulart: entre a memória e a história. Rio de Janeiro: Editora FGV, 2006. 
FILGUEIRAS, J. M. A Educação Moral e Cívica e sua produção didática: 1969-1993. 2006. 211f. Dissertação de Mestrado, Pontifícia Universidade Católica de São Paulo (PUC/SP), 2006.

FOUCAULT, M. Microfísica do Poder. Rio de Janeiro: Graal, 2008.

JAKOBSON, R. Linguística e Comunicação. 24.ed. São Paulo: Cultrix, 2007.

ORLANDI, E. P. Análise de discurso: princípios e procedimentos. Campinas: Pontes, 1999.

PÊCHEUX, M. A Análise do Discurso: Três Épocas (1983). In: GADET, F.; HAK, T. Por uma análise automática do discurso: Uma introdução à obra de Michel Pêcheux. Campinas: Editora da Unicamp, 1997. (p.311-319).

. Semântica e discurso: Uma crítica à afirmação do óbvio. Campinas: Editora da Unicamp, 1988.

REZENDE, M. J. A ditadura militar no Brasil: repressão e pretensão de legitimidade: 19641984. Londrina: Eduel, 2013.

SILVA, T. T. Documentos de Identidades - Uma Introdução as Teorias de Currículo. Belo Horizonte: Autêntica, 2003.

* Professora doutora do Instituto Federal Sul-Rio-Grandense, Pelotas, Rio Grande do Sul, Brasil.

** Mestre em Educação e Tecnologia pelo Instituto Federal Sul-Rio-Grandense, Pelotas, Rio Grande do Sul, Brasil.

\section{Correspondência}

Márcia Helena Sauáia Guimarães Rostas - Instituto Federal Sul-Rio-Grandense, Campus Pelotas. Praça vinte de setembro, 455, Centro, CEP: 96015360, Pelotas, Rio Grande do Sul - Brasil.

E-mail:mrostas@hotmail.com - xande.abreu75@gmail.com

Recebido em 23 de outubro de 2015

Aprovado em 19 de novembro de 2015 